\title{
A Brief History of Anterior Cruciate Ligament Reconstruction
}

\author{
Nikolaos Davarinos, ${ }^{1}$ Barry James O’Neill, ${ }^{2}$ and William Curtin ${ }^{2}$ \\ ${ }^{1}$ Department of Trauma \& Orthopaedics, The Adelaide \& Meath Hospital, Tallaght, Dublin 24, Ireland \\ ${ }^{2}$ Department of Trauma \& Orthopaedics, Galway Regional Hospitals, Galway, Ireland
}

Correspondence should be addressed to Nikolaos Davarinos; davarinn@me.com

Received 10 December 2013; Accepted 17 March 2014; Published 17 April 2014

Academic Editor: Palaniappan Lakshmanan

Copyright (C) 2014 Nikolaos Davarinos et al. This is an open access article distributed under the Creative Commons Attribution License, which permits unrestricted use, distribution, and reproduction in any medium, provided the original work is properly cited.

\begin{abstract}
Reconstructions of the anterior cruciate ligament (ACL) are among the most frequently performed procedures in knee surgery nowadays. The history of ACL surgery can be traced as far back as the Egyptian times. The early years reflect the efforts to establish a viable, consistently successful reconstruction technique while, during the early 20th century, we witness an increasing awareness of, and interest in, the ligament and its lesions. Finally, we highlight the most important steps in the evolution of the ACL reconstruction surgery by discussing the various techniques spanning the years using not only autologous grafts (fascia lata, meniscal, hamstring, patella tendon, bone-patella tendon-bone, and double bundle grafts) but also synthetic ones and allografts.
\end{abstract}

\section{Introduction}

Rupture of the anterior cruciate ligament (ACL) is a common injury in active people, and one of the most common knee injuries in sports. It is estimated that the annual incidence of ACL injury is about 1 in 3,000 amongst the general population in the USA. That means more than 150,000 new ACL ruptures annually [1]. The healing response after ACL rupture is poor. Without surgical reconstruction the ACL deficient knee is limited. So are the patient's activities and such ACL deficiency can lead to future degenerative changes [2-5]. Nowadays, ACL reconstruction surgery is a major area of research worldwide. This is partly due to the large number of athletes being involved in professional sports where a fast recovery and rehab are essential to return quickly to the sport. It is also due to the greater awareness within the general public of their own healthcare matters and the higher expectations now evident in amateur sports-persons and non-sports-persons alike.

We present a brief history of ACL injury and the surgical measures taken to address it over the years as well as the modern ACL reconstruction techniques.

\section{The Early Years}

The cruciate ligaments have been known about since old Egyptian times and their anatomy was described in the famous Smith Papyrus (3000 BC). Hippocrates also (460$370 \mathrm{BC}$ ) mentioned the subluxation of the knee joint with ligament pathology, but Claudius Galen, a Greek physician in the Roman Empire, was the first to describe the true nature of the ACL [6].

Prior to Galen's description, it was believed that the cruciate ligaments were part of the nervous system, but Galen was the first to describe the ACL as being a structure that supports the joint and prevents abnormal knee motion. He called the cruciate ligaments genu cruciata but he did not describe in detail their function $[6,7]$.

In 1836, the Weber brothers from Goettingen in Germany noted an abnormal anterior-posterior movement of the tibia after transection of the ACL. They also described the roll and glide mechanism of the knee and the tension pattern of the different bundles of the cruciate ligaments and, to our knowledge, were the first to describe that each bundle of the ACL was tensioned in different degrees of flexion of the knee joint [6]. 
In 1845, Amade Bonnet (1809-1858) of Lyon, France, published his first cadaveric studies for the mechanism of knee ligament injuries in his treatise on the treatment of joint diseases [6]. The first recorded description of rupture of the ACL, however, was by Stark in 1850 [8].

In 1875, the Greek Georgios C. Noulis [6] described the technique of the Lachman test for the first time. He wrote: "fix the thigh with one hand, while with the other hand hold the lower leg just below the knee with the thumb in front and the fingers behind. Then, try to shift the tibia forward and backward. When only the anterior cruciate ligament is transected, this forward movement is seen when the knee is barely flexed, whereas a backward movement is noted in 110 degrees of flexion when the posterior cruciate ligament is transected." His 110 degrees of flexion would translate into 70 degrees of flexion today since at that time they used 180 degrees as full extension.

In 1879, Paul Segond described an avulsion fracture of the anterolateral margin of the tibial plateau. This is routinely associated with ACL disruption. This fracture is now known universally as a Segond fracture and is considered pathognomonic for ACL tears.

In 1900, Battle first reported an ACL repair. It was done two years earlier during treatment for dislocation of the knee. The results were satisfactory. No further description was made [7].

Battle published the first report and Mayo-Robson performed the first repair.

In 1903, he reported the repair of both cruciate ligaments of the knee in a 41-year-old miner. A diagnosis of rupture of the anterior and posterior cruciate ligaments was made. Further arthrotomy revealed that the ligaments had been avulsed from their femoral attachments and they were duly repaired with catgut sutures. After some weeks of cast immobilisation, the knee was allowed to move and six years postoperatively the patient reported the knee to be "perfectly strong" [9].

Mayo-Robson felt that this case should be published and that surgical repair was both "feasible and hopeful." Yet later in 1903, F Lange of Munich attempted to replace an ACL using braided silk attached to the semitendinosus as a ligament substitute. This ultimately failed. The importance of the anterior cruciate ligament (ACL) was recognised by Fick as early as 1911 [10].

In 1913, Goetjes produced a detailed study of ruptures of the cruciate ligaments [7]. He discussed ligament function and mechanisms of rupture, as determined by cadaver studies. He advocated repair for the acute injury and conservative treatment for chronic ruptures. By 1916 Jones [11] had remarked that stitching the ligaments is absolutely futile: "Natural cicatricial tissue... is the only reliable means of repair." Jones' early observation was confirmed 60 years later by Feagin and Curl [12] when they published their longterm follow-up of West Point cadets who had had ACL repair during their college years.

They concluded: "long-term follow-up evaluations do not justify the hope... that anatomic repositioning of the residual ligament would result in healing." Such views led to a trend away from primary ACL repair (without augmentation) and instead towards the concept of immediate reconstruction of the ACL.

\section{Autologous Fascia Lata and Meniscal Grafts}

In 1912, KH Giertz operated on a 13-year-old girl with a totally unstable knee. She had septic arthritis of her knee when she was one year old. First, he corrected the fixed flexion deformity of 45 degrees by an osteotomy. Two weeks later, he stabilised the knee with free transplanted strips of fascia lata, sutured on the medial side to the medial femoral epicondyle and to the tibial tubercle, and on the lateral side from the lateral epicondyle to the fibular head. Postoperatively the girl was asymptomatic and did not attend for follow-up for 6 months. For all practical purposes the knee was stable [13].

In 1917, Hey Groves published a short case report on reconstruction of the ACL [14]. He detached a strip of fascia lata from its insertion and directed it through a tunnel in the tibia. In the following year in 1918, Smith published a paper reporting on nine cases he had treated with Hey Groves' technique. Smith was critical of the incomplete nature of the construct, which failed to strengthen the medial collateral ligament. One year later, Hey Groves presented fourteen further cases in which he modified his technique by leaving the graft attached to the tibia and detaching it superiorly, following the same route as in the previous cases. Hey Groves in 1920 was the first to state clearly that flexion and extension of the knee affect tension within the ACL [14].

\section{The Hamstring Graft}

In 1934 the Italian orthopaedic surgeon Riccardo Galeazzi described a technique for ACL reconstruction using the semitendinosus tendon. The tendon was released from its musculotendinous junction and placed intra-articularly through a $5 \mathrm{~mm}$ diameter bone tunnel drilled in the tibial epiphysis and a tunnel drilled through the lateral femoral condyle, where it was fixed to the periosteum. Galeazzi used three incisions: one for harvesting of the semitendinosus tendon, another for arthrotomy, and a third laterally for fixation. He used a cast for 4 weeks and partially weight bearing for 6 weeks. He reported on three cases. One operated in 1932 had a follow-up of 18 months, and the final outcome was a stable knee with full extension and only a mild reduction of flexion. Galeazzi was the first that ever published the usage of hamstrings tendon autograft in ACL reconstruction [15].

In 1939 Macey reported on using the semitendinosus tendon for the reconstruction of the ACL [16]. Only the tendinous portion of the semitendinosus muscle was harvested. During harvesting Macey stopped short of the musculotendinous junction and attached the graft with the knee held in full extension. For many years it was believed that Macey was the first one to ever use hamstrings in ACL reconstruction. The Orthopaedic community had failed to take into consideration Galeazzi's publication 5 years earlier.

In 1950, Lindemann used the semitendinosus tendon as dynamic stabilizer of ACL deficient knees [17]. Augustine reported a similar procedure [18]. McMaster et al. in 1974 
used the gracilis tendon alone [19]. It was left attached distally, pulled through the tibial and femoral tunnels, and fixed to the lateral condyle using a staple.

\section{Patellar Tendon Grafts}

In 1935, Campbell reported the first use of a tibia-based graft of the medial one- third of the patellar tendon, the prepatellar retinaculum, and a portion of the quadriceps tendon [20].

Campbell's technique involved the drilling of two tunnels, one in the tibia and one in the femur. The graft was sutured to the periosteum at the proximal end of the femoral tunnel. The procedure did not achieve widespread approval immediately. It was reintroduced by MacIntosh a few years later.

In 1944, Abbott noted that, in the absence of a fracture, examination of the knee joint was all too often superficial and cursory, with many ligamentous injury patterns grouped together as "internal derangements of the knee" and treated inadequately [21]. He advised that to avoid the later development of a painful, unstable joint with recurrent effusions, subsequent arthritic changes, and the attendant permanent disability, "a far greater precision in diagnosis and therapy is a necessity in a joint of such manifold complexity" [21].

\section{Bone-Patellar Tendon-Bone Grafts}

In 1963 Jones published a new surgical technique for the reconstruction of an irreparably damaged ACL [22]. Jones commented that while the need for surgical reconstruction of an irreparably torn ACL had long been appreciated, there was a need for a satisfactory technique to address the problem. The technique described was considered simpler and more "nearly physiological" than previous techniques. Jones described his technique as having the greatest application to old injuries, whilst suggesting that surgical repair was still the procedure of choice for acute injuries. The Jones procedure uses a medial parapatellar incision extending from one inch distal to the patella to just distal to the tibial tubercle. After drilling of a femoral tunnel, the middle third of the patellar tendon is then incised throughout its length, with the incisions continuing proximally across the patella and into the quadriceps tendon. A saw is then used to cut a triangular block of bone from the superficial cortex of the patella in line with the longitudinal incisions. The articular surface of the patella is not breached. In this manner, a graft consisting of a bone block from the patella and the central one-third of the patellar tendon is created, which is still in continuity with the tibia through the tibial insertion of the patellar tendon. This graft is then passed through the femoral tunnel, embedding the patellar component of the graft within the femoral tunnel, when pulled taut patellar tendon and the skin incision are then closed. Jones reported on 11 patients who underwent this procedure with excellent clinical outcomes.

Criticism of the technique centered around the fact that because the graft was so short, the femoral tunnel had to be drilled at the anterior margin of the notch and not at the insertion of the native ACL. The technique was simple, however, and caused minimal surgical trauma and so gained widespread acceptance.

Brückner described a similar technique in 1966, using the medial one-third of the patellar tendon [23]. The graft, harvested with a patellar bone block, was left attached to the tibia and then passed through a tibial tunnel, giving the graft more working length than in Jones' technique. After being passed through the joint, the graft was then placed in a socket in the femur and secured to the lateral aspect of the lateral femoral condyle of the femur with sutures passing through a button.

By 1969, Franke had further developed the techniques described by Jones and Bruckner. Franke pioneered the use of free bone-patellar tendon-bone graft consisting of onequarter of the patellar tendon with blocks of bone derived from the patella and proximal tibia at opposite ends of the graft [24]. His graft was fixed with a wedge-like piece of bone anchored in the tibial plateau and a shell-like piece of bone implanted into the femoral condyle. Although very similar to the Jones and Bruckner techniques, this was the first description of a free graft used in this manner.

Marshall et al. in 1979 also used the central third of the patellar tendon but left it distally attached, and they added for length a strip of the quadriceps tendon, which was secured in the over-the-top position to the lateral condyle [25].

By the 1990s the technique of using a free bone-patellar tendon-bone graft harvested from the central one-third of the patella became the "Gold Standard" of treatment. This technique was broadly termed the Jones Procedure in reference to the pioneering work done by Kenneth Jones in the 1960s [22]. It was popular because it was relatively simple and because it yielded consistently good results. During this period researchers devised the metal interference screw as a form of tibial and femoral graft fixation. Bioabsorbable interference screws soon followed.

\section{Synthetic Grafts}

Benson suggested the potential biological and biomechanical significance of pure carbon in 1971 [26]. During the 1970s and early 1980s, a group from Cardiff experimented extensively with the use of carbon implants as an agent for the induction of new tendon synthesis in animal models [27-30]. Jenkins argued that "since a high proportion of the tissues of living organisms is composed of carbon compounds it would not perhaps be surprising that implants of the pure element should be well tolerated by these tissues" [29]. Initial results were promising with new tendon being formed around the carbon grafts at three months after implantation and no obvious clinical dysfunction in an ovine model [29]. Jenkins et al. concluded that filamentous carbon is accepted in living tissues with virtually no adverse reaction and that it can be used to induce the formation of new tendon or ligament with a physical strength equal to that of the normal structure [29]. The implants were extremely well tolerated in the ovine model with regard to foreign body response, and this encouraged the Cardiff group to progress to clinical trials in the human lower limb [31]. This study included two ACL reconstructions 
in isolation and thirty-one combined knee ligament procedures. The two ACL reconstructions were reviewed yearly postoperatively (maximum three years) and both reported a significant improvement in the function of their knees. The only complication documented in this preliminary report was of sinus formation overlying graft material in 2 ankles where the graft was considered too superficial. No complications were reported in the knee group.

In 1983 Rushton et al. reported the clinical, arthroscopic, and histological findings in ten knees that had undergone ACL reconstruction using a carbon-fibre graft [32]. Carbonfibre ACL grafts had been implanted into thirty-nine patients and the ten reported cases had experienced pain and discomfort postoperatively. All ten patients had synovitis with evidence of carbon-fibre in the joint. Occasionally, the fibre stained the articular surface and menisci. The femoral notch of some patients contained inflamed synovium. Such synovium was stained black. In some patients a "new ligament" appeared to have formed but gentle probing with a blunt hook revealed this to be a thin, fibrous sheath covering unchanged carbon-fibre graft. Histologically two patients demonstrated a fibroblastic response to the carbon-fibre. Five patients showed evidence of chronic synovial inflammation and papillary proliferation of the synovium was present in all ten knees. A mild foreign-body giant-cell reaction to the carbon-fibre filaments and haemosiderin was seen in surface cells of the synovium, in macrophages, and around some fragments of carbon-fibre. Other complications included ulceration of the skin over subcutaneous carbon-fibre knots used to secure the graft, similar to the findings of the Jenkins study three years earlier [31].

\section{The Use of Allograft}

During the 1980s a remarkable interest developed in the use of allograft tissue for ACL reconstruction. The first experimental published studies concerning the mechanical, biological, and functional properties [33-37] were compensatory and this led sports medicine surgeons to adopt allografts in ACL reconstruction in humans.

Webster and Werner in 1983 conducted a study on dogs where they harvested flexor tendons from the forepaws and hind-paws of mongrel dogs [33]. These tendons were freezedried and then thawed, rehydrated, and implanted in recipient dogs as an ACL substitute graft. The purpose of the study was to ascertain whether or not freeze-dried grafts functioned as well as autografts over time. The use of allografts in theory would decrease the surgical morbidity associated with autograft harvest and would also allow for more precise graft size, shape, and quantity to be implanted than would autograft. Webster and Werner reported preliminary results similar to those for patellar tendon graft for graft strength and similar to normal ACL for mode of failure.

In 1985 Curtis et al. reported on a similar study, where freeze-dried fascia lata grafts were implanted in dogs as an ACL substitute graft [34]. All grafts were found to be intact at sacrifice with no overt evidence of biologic incompatibility. The knees displayed only mild instability to clinical testing without evidence of arthrosis. Histologically, the grafts appeared to function as collagenous scaffolding for revascularization and fibrovascular creeping substitution. Shino et al. echoed these findings. They found no significant differences between the mechanical properties of allografts and autografts and also reported no evidence of implant rejection [35].

Nikolaou et al. in 1986 seemed so sure of the future of freeze-dried allografts that they attempted to design and implement an experimental model for testing the feasibility of cryopreserved ACL allotransplantation [36]. Groups of dogs were used to evaluate the effect of cryopreservation on ligament strength and to compare the relative performance of both autograft and allograft ACL transplants up to 18 months after implantation. The ligaments were examined mechanically, histologically, and microangiographically. They reported that the cryopreservation process and duration of storage had no effect on the biomechanical or structural properties of the ligament. The mechanical integrity of the allografts was similar to that of the autografts, with both achieving nearly $90 \%$ of control ligament strength by 36 weeks. Revascularization approached normal by 24 weeks in both autograft and allograft. No evidence of structural degradation or immunological reaction was seen. Based on these results, Nikolaou et al. believed that a cryopreserved ACL allograft could provide the ideal material for ACL reconstruction and so outlined a surgical technique for harvesting and implanting this graft clinically.

In 1987 Jackson et al. reported disappointing results of implanted freeze-dried bone-ACL-bone graft in goats [37].

By 1991, however, the same group reported much better results in a similar trial whereby the graft material was frozen in situ and then subjected to a freeze-thaw process whereby the graft material was devitalised and devascularised prior to harvesting [38]. This resulted in a significant increase in graft strength and a decrease in knee laxity at six weeks and six months. The authors deduced that the loss of strength seen in allografts postoperatively was not a result of the freezing and revascularisation process, but rather the consequence of improper orientation and tensioning of the graft. They concluded that techniques of implantation that precisely provide proper orientation and tensioning of the graft might minimise the loss of strength.

During the 1980s, techniques for arthroscopic ACL reconstruction were becoming increasingly popular. There were two distinct schools of thought with regard to this. Some surgeons preferred the outside-in method, where the ligament is routed into the joint through a femoral tunnel [39, 40]. Yet other surgeons preferred the inside-out technique, where the ligament is routed from inside the joint into a femoral socket [41]. Despite the differing techniques, the 1980s were a time when arthroscopic ACL reconstruction became popularised, leading to a much better understanding of the ligament and its sites of attachment.

\section{The Double-Bundle graft}

The Jones procedure did of course have its drawbacks, including pain at the graft donor site and stiffness within 
the extensor apparatus of the knee. This led to further experimentation with the use of hamstring grafts.

In 2003 Marcacci et al. described a double-bundle gracilis and semitendinosus graft that they claimed guaranteed a more anatomic ACL reconstruction and avoided the use of hardware for graft fixation [42].

The technique is designed to reproduce the kinematic effect of both anteromedial and posterolateral bundles of the ACL with a 4-bundle reconstruction. Modifications of this technique have been described by a number of authors [4348]. Research into this area continues, and although many surgeons now practice variations of this technique, many ACL reconstruction procedures are still done using bonepatellar tendon-bone graft.

\section{Conclusion}

The history of ACL reconstruction can be traced as far back as the Egyptians times. Research and innovation abound in this area, with improvements in clinical outcomes being achieved constantly. Knowledge of the evolution of ACL reconstruction is invaluable to those who continue to try to improve the outcomes of the procedure, in order to further the advances already made, but also to reduce the risk of repeating the mistakes of the past.

\section{Conflict of Interests}

The authors declare that they have no conflict of interests, financial or otherwise, with regard to this paper. It has not been submitted to any other journal for consideration for publication.

\section{References}

[1] K. Miyasaka, D. Daniel, M. Stone, and P. Hirshman, "The incidence of knee ligament injuries in the general population," The American Journal of Knee Surgery, vol. 4, pp. 3-8, 1991.

[2] D. L. Butler, "Anterior cruciate ligament: its normal response and replacement," Journal of Orthopaedic Research, vol. 7, no. 6, pp. 910-921, 1989.

[3] C. Frank, D. Amiel, S. L.-Y. Woo, and W. Akeson, "Normal ligament properties and ligament healing," Clinical Orthopaedics and Related Research, vol. 196, pp. 15-25, 1985.

[4] F. R. Noyes, L. A. Mooar, C. T. Moorman III, and G. H. McGinniss, "Partial tears of the anterior cruciate ligament. Progression to complete ligament deficiency," Journal of Bone and Joint Surgery. British, vol. 71, no. 5, pp. 825-833, 1989.

[5] S. M. Strickland, J. D. MacGillivray, and R. F. Warren, "Anterior cruciate ligament reconstruction with allograft tendons," Orthopedic Clinics of North America, vol. 34, no. 1, pp. 41-47, 2003.

[6] V. Chouliaras and H. H. Passler, "The history of the anterior cruciate ligament from Galen to double-bundle acl reconstruction," Acta Orthopaedica et Traumatologica Hellenica.

[7] G. A. Snook, "A short history of the anterior cruciate ligament and the treatment of tears," Clinical Orthopaedics and Related Research, vol. 172, pp. 11-13, 1983.

[8] J. Stark, "Two cases of ruptured crucial ligaments of the kneejoint," The Edinburgh Medical and Surgical, vol. 5, pp. 267-271, 1850.
[9] A. W. M. Robson, "Ruptured crucial ligaments and their repair by operation," Annals of Surgery, vol. 37, pp. 716-718, 1903.

[10] H. E. Cabaud, "Biomechanics of the anterior cruciate ligament," Clinical Orthopaedics and Related Research, vol. 172, pp. 26-31, 1983.

[11] R. Jones, "Disabilities of the knee joint," British Medical Journal, vol. 2, pp. 169-173, 1916.

[12] J. A. Feagin Jr. and W. W. Curl, "Isolated tear of the anterior cruciate ligament: 5 year follow up study," American Journal of Sports Medicine, vol. 4, no. 3, pp. 95-100, 1976.

[13] K. H. Giertz, "Über freie Transplantation der Fascia lata als Ersatz für Sehnen und Bänder," Deutsche Zeitschrift für Chirurgie, vol. 125, no. 5-6, pp. 480-496, 1913.

[14] "The classic. Operation for repair of the crucial ligaments Ernest W. Hey Groves, MD., F.R.C.S.," Clinical Orthopaedics and Related Research, vol. 147, pp. 4-6, 1980.

[15] R. Galleazzi, "La ricostituzione dei ligamenti cociati del ginocchio," Atti e Memorie della Società Lombarda di Chirurgia, vol. 13, pp. 302-317, 1924.

[16] H. Macey, "A new operative procedure for the repair of ruptured cruciate ligaments of the knee joint," Surgery, Gynecology \& Obstetrics, vol. 69, pp. 108-109, 1939.

[17] K. Lindemann, "Plastic surgery in substitution of the cruciate ligaments of the knee-joint by means of pedunculated tendon transplants," Zeitschrift für Orthopädie und ihre Grenzgebiete, vol. 79, no. 2, pp. 316-334, 1950.

[18] R. W. Augustine, "The unstable knee," The American Journal of Surgery, vol. 92, no. 3, pp. 380-388, 1956.

[19] J. H. McMaster, C. R. Weinert Jr., and P. Scranton Jr., "Diagnosis and management of isolated anterior cruciate ligament tears: a preliminary report on reconstruction with the gracilis tendon," Journal of Trauma, vol. 14, no. 3, pp. 230-235, 1974.

[20] W. Campbell, "Repair of the ligaments of the knee: report of a new operation for the repair of the anterior cruciate ligament," Surgery, Gynecology \& Obstetrics, vol. 62, pp. 964-968, 1936.

[21] L. C. Abbott, J. B. M. Saunders, F. C. Bost, and C. E. Anderson, "Injuries to the ligaments of the knee joints," The Journal of Bone and Joint Surgery. American, vol. 26, pp. 503-521, 1944.

[22] K. G. Jones, "Reconstruction of the anterior cruciate ligament using the central one-third of the patellar ligament," Journal of Bone and Joint Surgery. American, vol. 52, no. 4, pp. 838-839, 1970.

[23] H. Brückner, "A new method for plastic surgery of cruciate ligaments," Chirurg, vol. 37, no. 9, pp. 413-414, 1966.

[24] K. Franke, "Clinical experience in 130 cruciate ligament reconstructions," Orthopedic Clinics of North America, vol. 7, no. 1, pp. 191-193, 1976.

[25] J. L. Marshall, R. F. Warren, T. L. Wickiewicz, and B. Reider, "The anterior cruciate ligament: a technique of repair and reconstruction," Clinical Orthopaedics and Related Research, vol. 143, pp. 97-106, 1979.

[26] B. J. Benson, "Elemental carbon as a biomaterial," Journal of Biomedical Materials Research, vol. 5, no. 6, pp. 41-47, 1972.

[27] I. W. Forster, Z. A. Ralis, B. McKibbin, and D. H. R. Jenkins, "Biological reaction to carbon fiber implants: the formation and structure of a carbon-induced 'neotendon," Clinical Orthopaedics and Related Research, vol. 131, pp. 299-307, 1978.

[28] D. H. R. Jenkins, “The repair of cruciate ligaments with flexible carbon fibre. A longer term study of the induction of new ligaments and of the fate of the implanted carbon," Journal of Bone and Joint Surgery. British, vol. 60, no. 4, pp. 520-522, 1978. 
[29] D. H. R. Jenkins, I. W. Forster, B. McKibbin, and Z. A. Ralis, "Induction of tendon and ligament formation by carbon implants," Journal of Bone and Joint Surgery. British, vol. 59, no. 1, pp. 53-57, 1977.

[30] R. N. Tandogan, Ö. Taşer, A. Kayaalp et al., "Analysis of meniscal and chondral lesions accompanying anterior cruciate ligament tears: relationship with age, time from injury, and level of sport," Knee Surgery, Sports Traumatology, Arthroscopy, vol. 12, no. 4, pp. 262-270, 2004.

[31] D. H. R. Jenkins and B. McKibbin, "The role of flexible carbonfibre implants as tendon and ligament substitutes in clinical practice. A preliminary report," Journal of Bone and Joint Surgery. British, vol. 62, no. 4, pp. 497-499, 1980.

[32] N. Rushton, D. J. Dandy, and C. P. E. Naylor, "The clinical, arthroscopic and histological findings after replacement of the anterior cruciate ligament with carbon-fibre," Journal of Bone and Joint Surgery. British, vol. 65, no. 3, pp. 308-309, 1983.

[33] D. A. Webster and F. W. Werner, "Freeze-dried flexor tendons in anterior cruciate ligament reconstruction," Clinical Orthopaedics and Related Research, vol. 181, pp. 238-243, 1983.

[34] R. J. Curtis, J. C. Delee, and D. J. Drez Jr., "Reconstruction of the anterior cruciate ligament with freeze dried fascia lata allografts in dogs. A preliminary report," American Journal of Sports Medicine, vol. 13, no. 6, pp. 408-414, 1985.

[35] K. Shino, T. Kawasaki, and H. Hirose, "Replacement of the anterior cruciate ligament by an allogeneic tendon graft. An experimental study in the dog," Journal of Bone and Joint Surgery. British, vol. 66, no. 5, pp. 672-681, 1984.

[36] P. K. Nikolaou, A. V. Seaber, and R. R. Glisson, "Anterior cruciate ligament allograft transplantation. Long-term function, histology, revascularization, and operative technique," American Journal of Sports Medicine, vol. 14, no. 5, pp. 348-360, 1986.

[37] D. W. Jackson, E. S. Grood, B. T. Cohn, S. P. Arnoczky, T. M. Simon, and J. F. Cummings, "The effects of in situ freezing on the anterior cruciate ligament: an experimental study in goats," Journal of Bone and Joint Surgery. American, vol. 73, no. 2, pp. 201-213, 1991.

[38] S. M. Howell, M. P. Wallace, M. L. Hull, and M. L. Deutsch, "Evaluation of the single-incision arthroscopic technique for anterior cruciate ligament replacement: a study of tibial tunnel placement, intraoperative graft tension, and stability," American Journal of Sports Medicine, vol. 27, no. 3, pp. 284-293, 1999.

[39] W. G. Clancy Jr., R. G. Narechania, and T. D. Rosenberg, "Anterior and posterior cruciate ligament reconstruction in rhesus monkeys. A histological, microangiographic, and biomechanical analysis," Journal of Bone and Joint Surgery. American, vol. 63, no. 8, pp. 1270-1284, 1981.

[40] F. R. Noyes, D. S. Matthews, P. A. Mooar, and E. S. Grood, "The symptomatic anterior cruciate-deficient knee. Part II. The results of rehabilitation, activity modification, and counseling on functional disability," Journal of Bone and Joint Surgery. American, vol. 65, no. 2, pp. 163-174, 1983.

[41] J. Gillquist and M. Odensten, "Arthroscopic reconstruction of the anterior cruciate ligament," Arthroscopy, vol. 4, no. 1, pp. 59, 1988.

[42] M. Marcacci, A. P. Molgora, S. Zaffagnini, A. Vascellari, F. Iacono, and M. Lo Presti, "Anatomic double-bundle anterior cruciate ligament reconstruction with hamstrings," Arthroscopy, vol. 19, no. 5, pp. 540-546, 2003.

[43] H. Asagumo, M. Kimura, Y. Kobayashi, M. Taki, and K. Takagishi, "Anatomic reconstruction of the anterior cruciate ligament using double-bundle hamstring tendons: surgical techniques, clinical outcomes, and complications," Arthroscopy, vol. 23, no. 6, pp. 602-609, 2007.

[44] G. Bellier, P. Christel, P. Colombet, P. Djian, J. P. Franceschi, and A. Sbihi, "Double-stranded hamstring graft for anterior cruciate ligament reconstruction," Arthroscopy, vol. 20, no. 8, pp. 890894, 2004.

[45] K. Yasuda, E. Kondo, H. Ichiyama, Y. Tanabe, and H. Tohyama, "Clinical evaluation of anatomic double-bundle anterior cruciate ligament reconstruction procedure using hamstring tendon grafts: comparisons among 3 different procedures," Arthroscopy, vol. 22, no. 3, pp. 240-251, 2006.

[46] S.-J. Kim, K.-A. Jung, and D.-H. Song, "Arthroscopic doublebundle anterior cruciate ligament reconstruction using autogenous quadriceps tendon," Arthroscopy, vol. 22, no. 7, pp. 797.el797.e5, 2006.

[47] P. U. Brucker, S. Lorenz, and A. B. Imhoff, "Aperture fixation in arthroscopic anterior cruciate ligament double-bundle reconstruction," Arthroscopy, vol. 22, no. 11, pp. 1250.el-1250.e6, 2006.

[48] J. H. Ahn and S. H. Lee, "Anterior cruciate ligament doublebundle reconstruction with hamstring tendon autografts," Arthroscopy, vol. 23, no. 1, pp. 109.el-109.e4, 2007. 


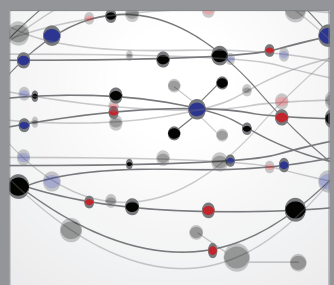

The Scientific World Journal
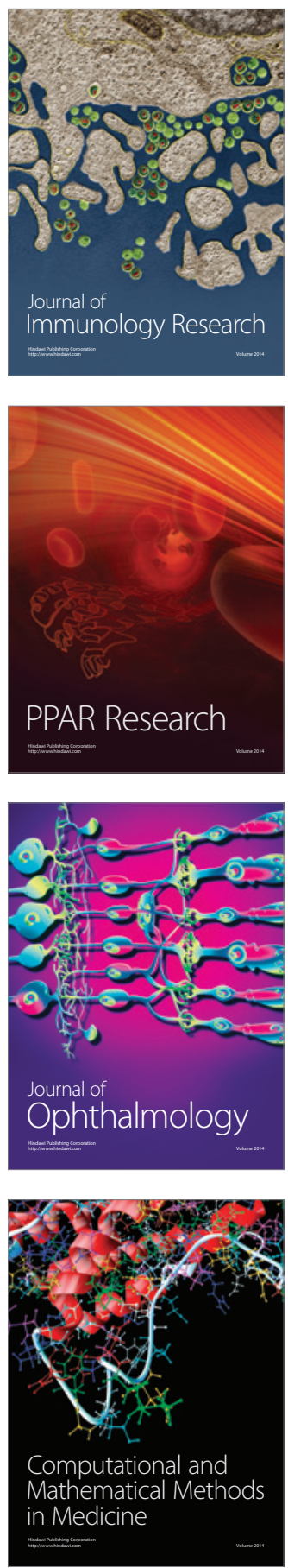

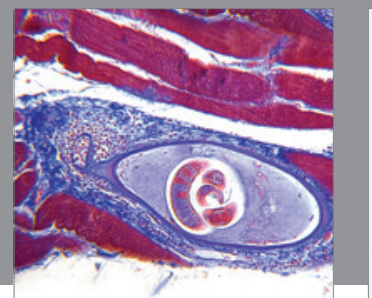

Gastroenterology

Research and Practice
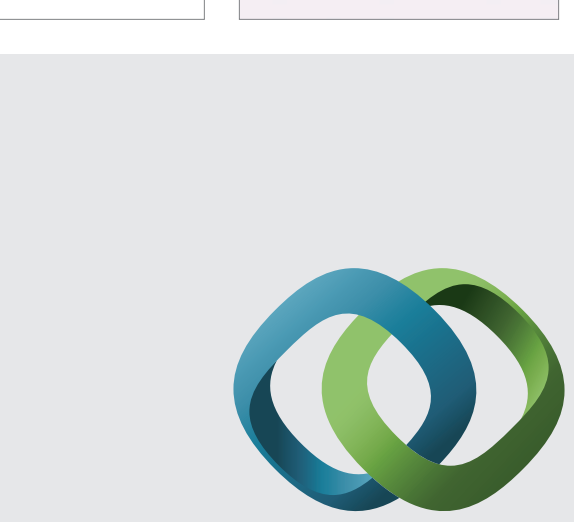

\section{Hindawi}

Submit your manuscripts at

http://www.hindawi.com
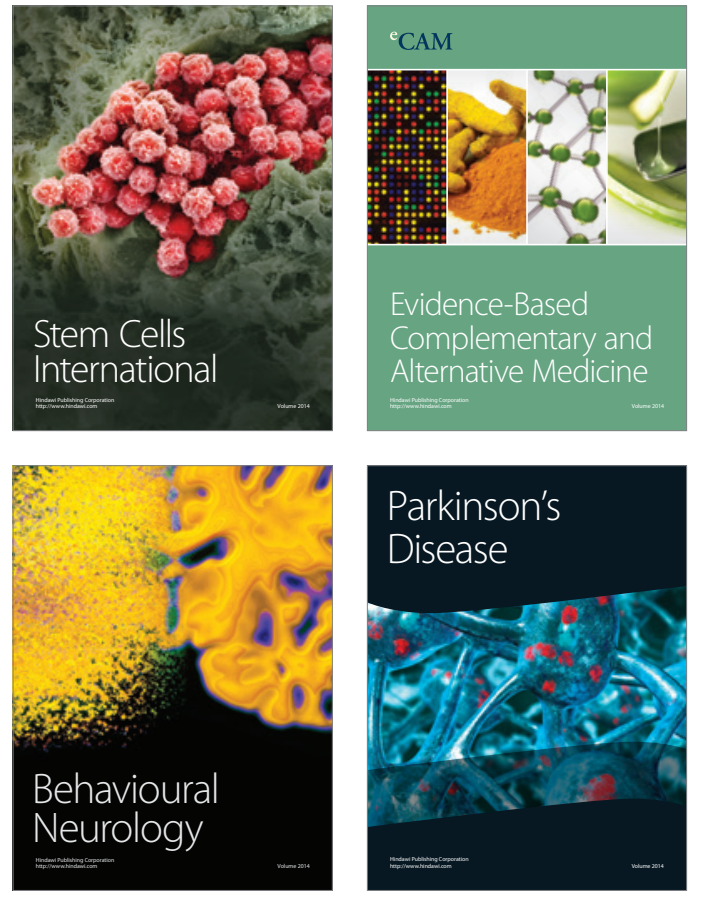
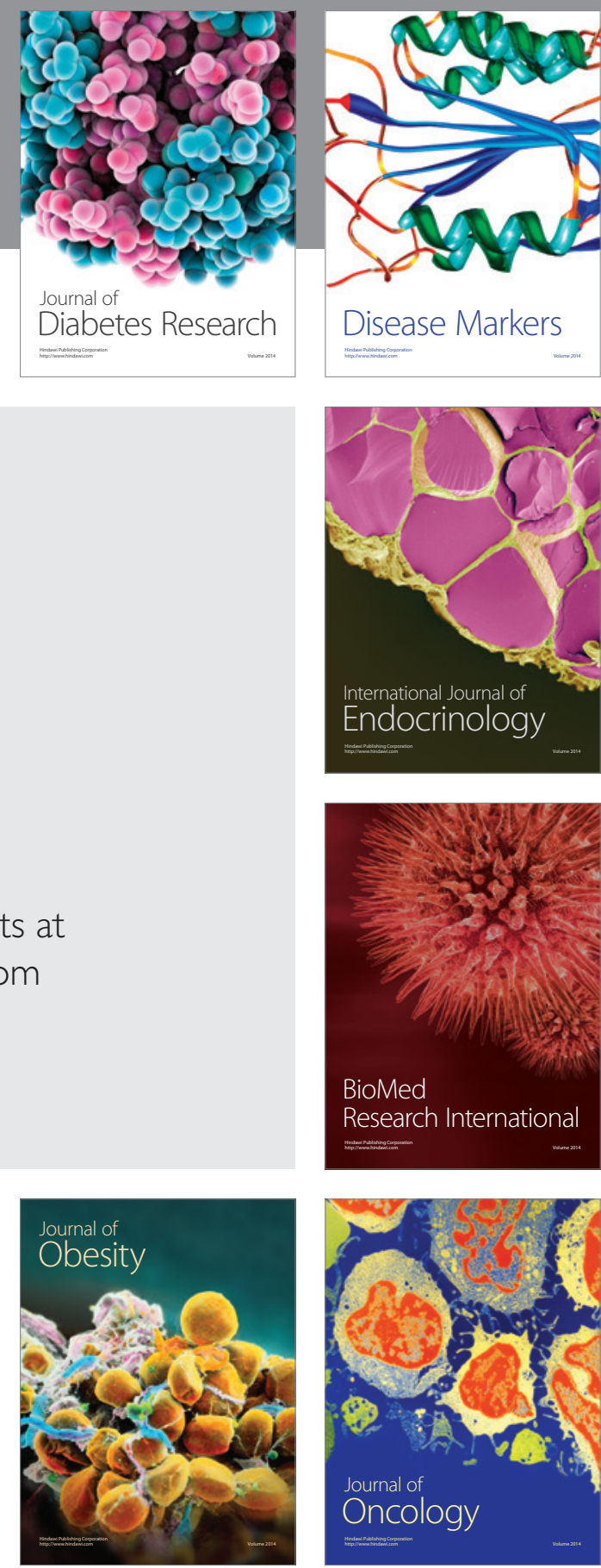

Disease Markers
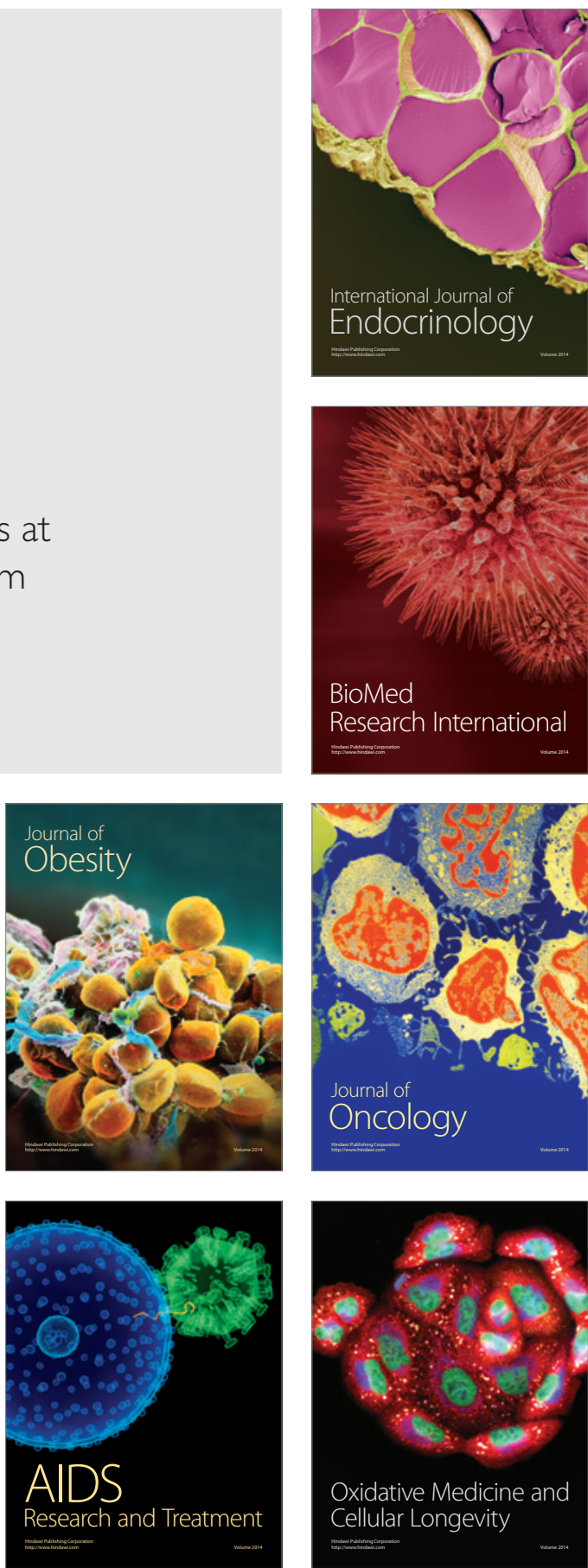